\section{CAMBRIDGE (U.S.) OBSERVATORY}

I $N$ two previous articles (NATURE, vol. x. pp. 186, 206) 1 we gave a siketch of the history of some of the principal observatories of the United States. Those which we then referred to are all more or less connected with the work of education. We shall now give some details of an observatory which has been enabled to make marked advances in independent research outside of its educational service ; we refer to that of Cambridxre, Massachusetts.

A look into the earlier annals of the observatory of Harvard repays the inquirer at the outset by revealing the interest in astronomical pursuits which was felt in the old Bay State many years before the founding of an observatory was practicable in the United States. In 1761 the Province sloop was fitted out at the public expense to convey a Harvard professor, Winthrop, to Newfoundland, to observe the transit of Venus of that year; and in the troublous times of 1780 the old "Board of War" fitted out the Lincoln galley to convey Prof. Williams and a party of students to Penobscot, to observe a solar eclipse. At so early a day was New England disposed to encourage scientific observations.

In 1805 , Mr. John Lowell, of Boston, was consulting with Delambre in Paris on astronomical observatories, and forwarding his information to the Hollis professor, Webber, who even then indulged the hope of seeing an observatory founded. But it was only in 1839 that an observatory was erected on the Dana estate, and the

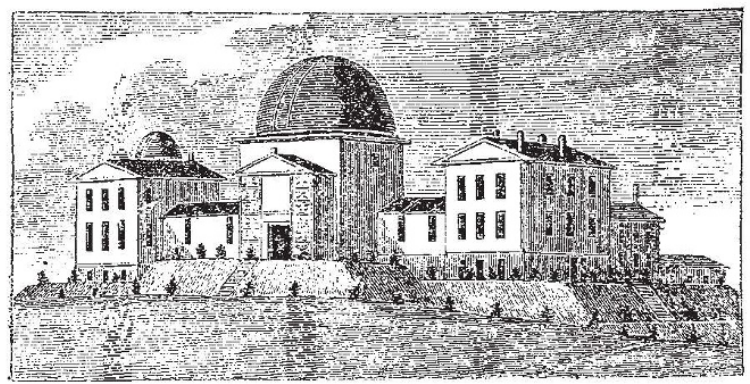

VIG. :-Cambridge Observatory.

observations which had been authorised by the United States Government to be made in connection with Lieut. Wilkes's exploring expedition were conducted by Prof. Bond until the year 1842 .

A new issue now arose. The sudden appearance of the splendid comet of 1843 was, happily, the occasion of final success in the founding of the present institution. Cambridue was immediately appealed to for information about this strange comet. But the observers had no parallactic instruments or micrometers of the least value for its observation. While they were endeavouring to obtain data to compute the comet's orbit, a meeting of citizens was held, under the sanction of the American Academy, to take measures for procuring a first-class equatorial; the needed amount of $\$ 20,000$ for the instrument was contributed in Boston, Salem, New Bedford, and Nantucket. The equatorial was ordered from Merz and Mähler, of Municb, and Harvard determined to erect a new observatory. The location selected was $80 \mathrm{ft}$. above tide-water, and $50 \mathrm{ft}$. above the plain where the soil was found favourable for the stability of piers for the instruments. In 1844 the buildings were occupied, and an equatorial of 44 in. focal length and $2 \frac{1}{2}$ in. aperture, and a transit instrument loaned by the United States, were temporarily mounted for observations until the arrival of the great refractor. This was placed in position June 24, 1847. Among the earlier objects on which systematic observations were made with the new instrument were the nebulæ of Andromeda and Orion. "These nebula," said Prof. Bond, "were regarded as strongholds of the nebular theory; that is, the idea first suggested by the elder Herschel of masses of matter in process of condensation into systems." Orion's nebula had not yielded to either of the Herschels, armed even with their excellent reflectors, nor had it shown the slightest trace of resolvability under Lord Rosse's $3 \mathrm{ft}$. reffector. Bond announced, on Sept. 27,1847 , that the Cambridge refractor, set upon the trapezium under a power of 200 , resolved this part of it into bright points of light, with a number of separate stars too great to be counted. With a power of 600 , "Struve's Companion" was distinctly separated from its primary, and other stars were seen as double.

Within a few years yet more brilliant discoveries followed. Among them the inner ring of Saturn and its eighth satellite; the coincidence of which latter discovery on the same day (Sept. 19, 1848 ) at Cambridge and in England in no wise detracted from the honour due to each discoverer. It required, in those times, weeks before the discovery, indeed, could be mutually made known.

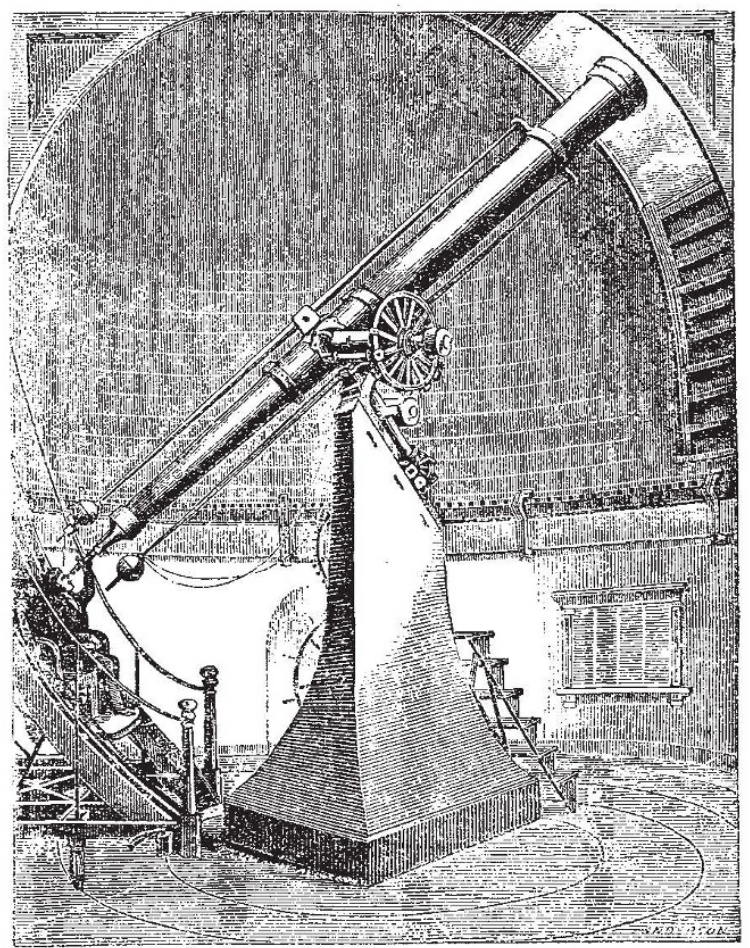

FIG. 2:-Cambridge Equatorial,

In 1850 Prof. W. C. Bond, with his sons, invented the spring governor, which gave an equable rotatory motion to the revolving cylinder of the chronograph. The observatory having been placed in $I 849$ on a permanent endowment by a legacy of $\$ 100,000$ from Mr. E. B. Phillips, a young graduate of Harvard, and a fund for printing its results having been also provided by will of the Hon. Josiah Quincy, jun., the reports of the first systematic zone ibservations appeared in 1855 as Part II. of vol. i. of the "Annals." This zone catalogue comprises 5,500 stars situated between the equator and $0^{\circ} 20^{\prime}$ north declination. The second volume, published in 1857 , embraced chiefly observations of the planet Saturn made during a period of ten years. The second part of this rol. ii. is a zone catalogue of 4,484 more stars in the same zones as those observed before i854. It was not printed until the year 1867. The splendid vol. iii., published in 1862 , is a quarto of 372 pages, with fifty-one plates almost entirely illustrative of the great comet of the Italian astronomer Donati, which appeared in such different forms in America from those seen in England. 
The Great Nebula of Orion was the other chief object of the observatory up to the death, in 1849 , of Prof. W. C. Bond, the father, and thence to the death of the son, Prof. G. P. Bond, in 1865 . The observations of this constellation form the latest as yet published volume of the "Annals," issued, in 1867, under the supervision of Prof: T. H. Safford, then director of Dearborn Observatory, but formerly in charge at Harvard as assistant in the observatory. For Mr. G. P. Bond's work, and especially for his observations on Donati's comet, he received a gold medal from the Royal Astronomical Society in $1865 .^{1}$

Since the year 1866 , in which the present director, Prof. Joseph Winlock, took charge of the observatory, its work has been yet further most successfully extended into new fields of research, by his own labours, and those of his able assistants, Messrs. Searle, Rogers, and Peirce. Besides what is known as routine work of all observatories,

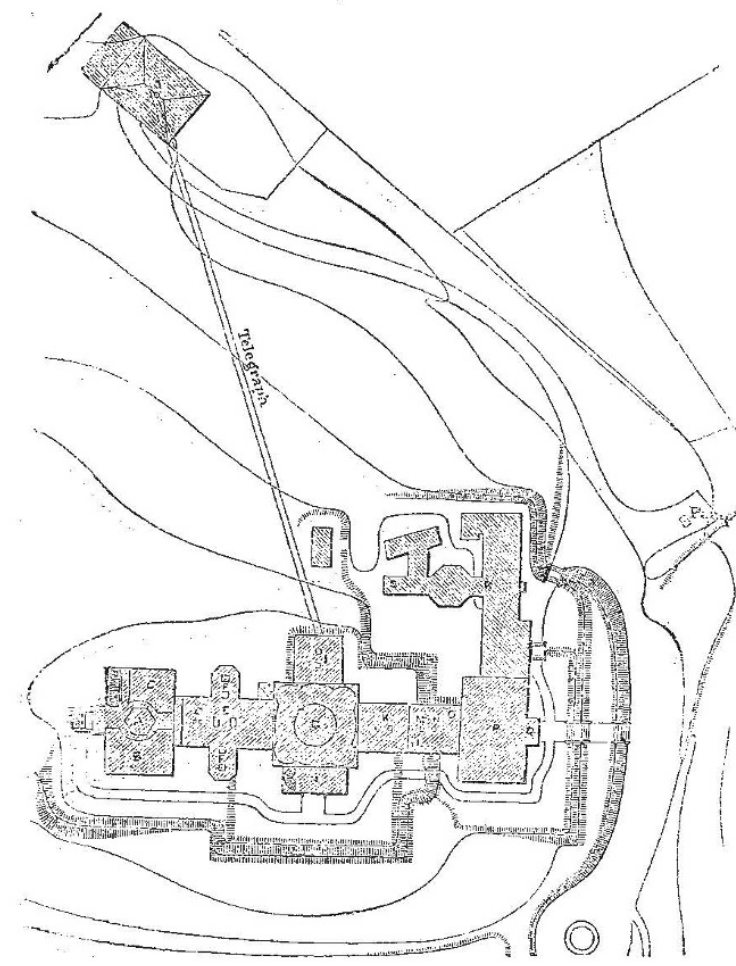

Fig. 3.-Ground plan of Cambridge Observatory. A, west equatorial ; $B$ library ; $C$, contputing-room ; D, west transit; $E$, new piers for new trasit citcle: $H$, collimator piers: G, east equatorial; H, grand entrance and stairs to east equatorial; $\mathrm{I}$, prime vertical room and morth clack; $K$, east transit : 1, soutli clock : M, east clock; $N$, Chrono



spectroscopic observations of the sun and of stars and nebilye, and the most careful photographs of the sun, have been frequent. Five hundred drawings of the sun were made between January 1872 and November 1873 and 500 careful drawings of solar prominences in the year I 873. To this work is to be added a great deal of labour given to the determination of longitude differences, and the observations, by Prof. Winlock, of the solar eclipse of I869, at Shelbyville, Kentucky, and that of I 870 , at Jere in Spain. The general reader, as well as the astronomer, cannot fail to be interested in the beautiful pictorial representations of these and of other astronomical phenomena which have been issued by subscription recently from Harvard.

I Mr. Bond was the first American, we believe, to be thus honoured with the gold medal of a foreign scientific society. Prof. Watson, of Anu Arbor and more recently Prot, Sinon. Newcomb, of the United States Naval Obscrvatory, have been the recipients of like honours; the former from the Society of London.
The great equatorial, made in 1847 by Merz and Mähler, of Munich, has an object-glass of 15 in. in diameter, and a focal length of $22 \mathrm{ft} .6 \mathrm{in}$. The power of its evepiece ranges from 100 to 2,000 ; the hour-circle is $I S$ in in diameter. The movable portion of the well-balanced instrument is estimated at three tons. Its original cost was about $\$ 20,000$. The sidereal motion given to this telescope is now secured by clockwork from Alvan Clark, which is spoken of by the observers as the only known "driving-clock worlking with perfect steadiness." The telescope rests on a central granite pier, in constructing which 500 tons of granite were used. It is $40 \mathrm{ft}$. high, and rests on a wide foundation of grouting $26 \mathrm{ft}$, below the ground surface, Upon the top of the pier is laid a circular cap-stone ro ft. in diameter, on which is the granite block, Io ft. high, bearing the metallic bed-plate. This instrument is in the central "Sears Tower."

The meridian circle was mounted in the west transit

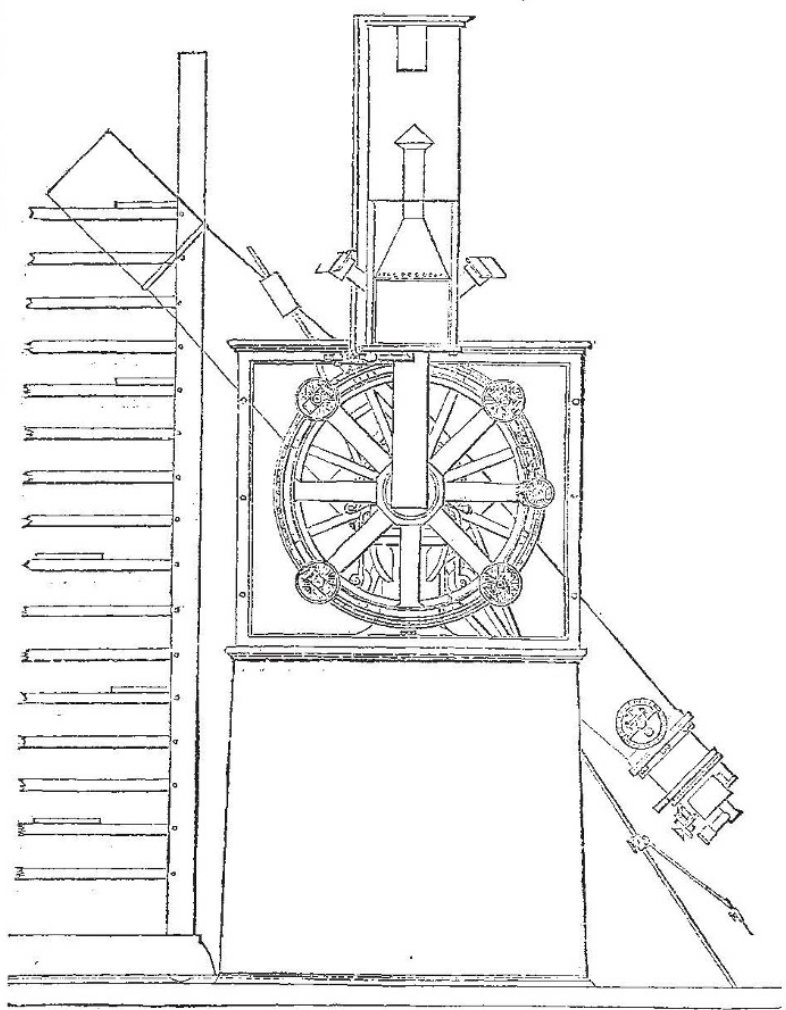

FrG. 4.-Cambridge Meridian Circle.

room in 1870 . It has modifications, introduced by prof. Winlock, not usually found in transit instruments, chiefly, that the graduated circles are directly above the piers, the bearings of the pivots being carried by iron standards; the axis friction rollers rest on rods rising from the base of the piers and counterpoised below the floor. The pivot circles and reading microscopes are protected by glass casing; the object-glasses of the transit and of each of its collimators, made by Clark, are each 8 in.

In the west dome is another Clark equatorial, made in I 870 , with an object-glass of $5 \frac{1}{2}$ in. In the east wing is the transit circle made in Prof. Bond's directorship, by Simms, of London. Its focal length is 65 in., its objectglass $4 \frac{1}{8}$ in.; its circles are $4 \mathrm{ft}$. in diameter, read by eight microscopes to single seconds. Cambridge possesses a number of more modern instruments, constructed to meet the wants of astronomical investigations at this day.

The spectroscopes, photometers, and photographic apparatus are peculiar in form and power. The spectro- 
scope used with the west equatorial in solar observations powerfully disperses the rays of light, which are carried twice through a train of prisms. In photographing the sun a lens of long focus is used, the light being thrown upon it by movable plane mirrors. This plan of Prof. Winlock's was adopted by the astronomers who went out under the U.S. Government to observe the Transit of $V$ venus in December, 1875 .

The photometer, or light measurer, made by Zöllner, has been used for three years by Assistant Prof. C. S.

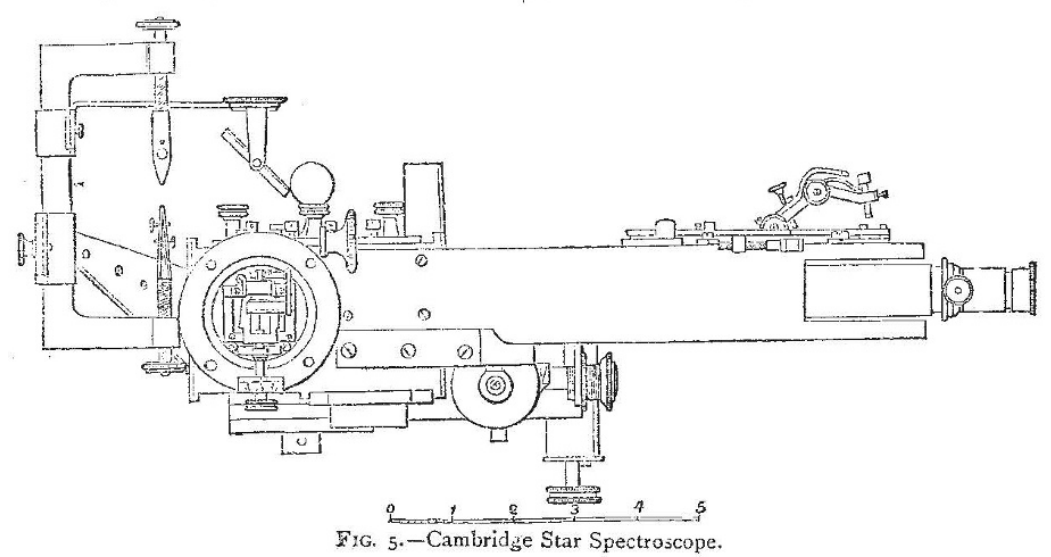

nitude is to be estimated. The secondary object is the prosecution of inquiriss with regard to the distribution of the stars in space, their magnitudes and variability.

The true time is daily given from this observatory to the State-house and other places in Boston, and by means of the telegraph lines to the whole of the New England States. It is received directly at noon each day without the intervention of any operator; the various lines being merely switched into the time line, the same click is heard at the same moment over the Eastern States.

Much more, however, than this is done for securing accuracy of time at any hour of the day. If anyone wishes to learn not only what the true time is, but whether his own watch is a good timekeeper, he may readily do so by a visit to the State-house in Boston. The arrangement for this, introduced by Prof. Winlock, is as follows:-The observatory clock is put in circuit at one end of a telegraph line, connected with which, at the State-house and other points, is an ordinary telegraph sounder. When the clock breaks the circuit by every second swing of the pendulum, a click of the armature of the sounder is heard at each of these points. The clock being so arranged that at every fifty-eighti second the break ceases, and at every even five minutes twelve breaks cease (no clicks being then heard), any person can, by listening to the sounder, compare his own watch with the standard clock. He can tell whether his watch is fast or slow by watching when the sounder ceases, the first click after the short pause being always the beginning of the minute, and the first click after the long pause the beginning of an even five minutes, as shown by the face of the clock in the distant observatory.

This standard motor clock is of course regulated with extreme care. It is customary, for the government of its rate of motion, to use shot of different sizes, which, according to the size, produce a change in the rate of the pendulum varying between $0^{\circ} 05$ and $0^{\circ} 10$ of a second per day. These are used as the astronomical correction for clock error may require. The time given by the standard clock thus regulated is that of the meridian near the State-house, sixteen seconds east of the observatory. Prof. Winlock considers that the use of the telegraph sounder gives a more satisfactory accuracy of time than can be given by other clocks which are put within the circuit and
Peirce. The design is the accurate measurement of the magnitudes of all stars in Argelander's Uranometria between $40^{\circ}$ and $50^{\circ}$ north declination, deternining these magnitudes on a scale of uniform ratios of light, so that the probable error of one observation shall not exceed the tenth of a single magnitude. The great object of this is, that throughout Europe and the northern part of the United States there will be constantly enough of accurately determined stars near the zenith to serve as comparisons for any star visible to the naked eye whose mag-

controlled, as is usual, by the standard clock; for in their case a variation in the strength of the electric current introduces an error in the beats of the pendulum, but the telegraph sounder must give the time with entire accuracy.

With so much before one at Cambridge of which interesting note could be made, one can do no more than attempt to trace its early and munificent endowment, its

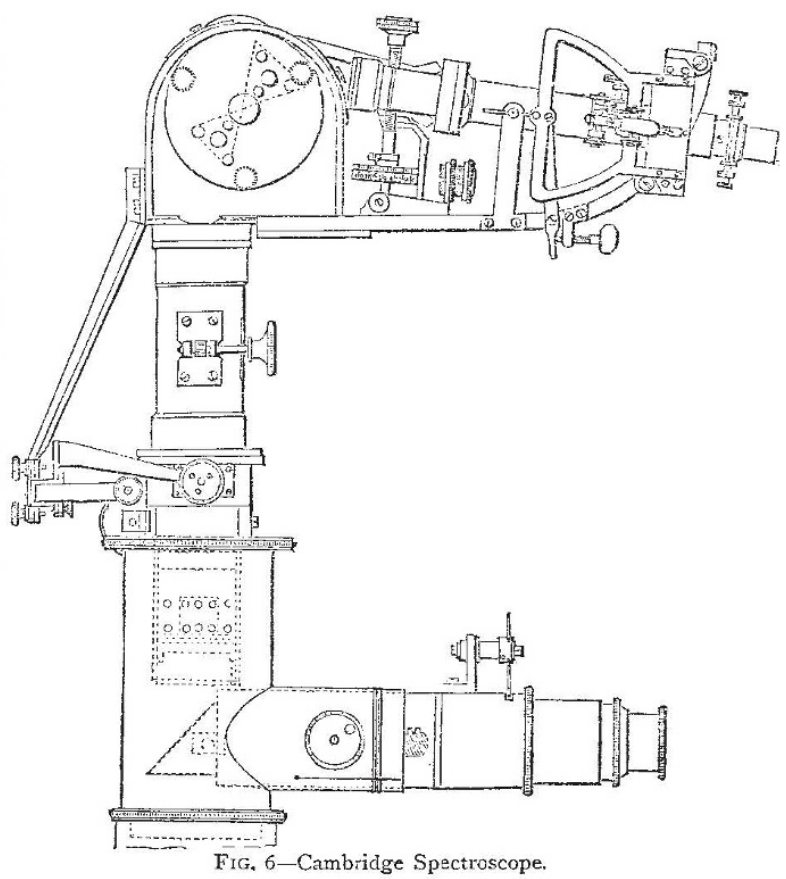

earliest discoveries under its first labourers, and the steady and recently very rapid advances not only in the highest objects of an observatory-exactness throughout extended series of observations-but in the exercise of professional skill in the invention and manufacture of the best appliances of the day for carrying on these investigations. 